\title{
Synthesis of Pd nanocrystals in phosphonium ionic liquids without any external reducing agents $\uparrow$
}

\author{
Hassan A. Kalviri and Francesca M. Kerton* \\ Received 25th November 2010, Accepted 25th January 2011 \\ DOI: $10.1039 / \mathrm{cogc00851f}$
}

Trihexyl(tetradecyl)phosphonium ionic liquids (ILs) are found to support the formation of $\operatorname{Pd}(0)$ nanoparticles without the addition of reducing agents such as $\mathrm{NaBH}_{4}$. The resulting particles are highly crystalline and have been characterized by a range of techniques including TEM and XRD. Their sizes are in the range $7 \pm 2 \mathrm{~nm}$. The particle formation process is highly dependent on the anion of the IL with no nanoparticles observed when the chloride derivative was used. Particle shape could be controlled through varying the anion of the IL and the Pd(II) precursor used.

Palladium chloride reagents gave truncated octahedron shaped particles in

trihexyl(tetradecyl)phosphonium dodecylbenzenesulfonate, whereas palladium acetate under the same conditions afforded a mixture of shapes including triangular plates. We propose that the presence of chloride anions in the reaction mixtures led to oxidative etching of the particles and that this process can be reduced in the presence of certain anion partners in the IL including bis(2,4,4-trimethylpentyl)phosphinate. Two possible reduction mechanisms based on reactions of the phosphonium cation are suggested for the formation of the $\operatorname{Pd}(0)$ species. The resulting nanoparticles are effective in catalyzing the Suzuki reaction of 4-bromotoluene and benzene boronic acid.

\section{Introduction}

Pd nanostructures have found many applications in science and engineering. Because of an increased surface area to volume ratio, nanostructures have more active sites compared with bulk materials. Therefore, nanomaterials are often more efficient in their applications, whether that be as catalysts, ${ }^{1}$ sensors or in other fields. For example, Pd nanostructures have been employed for hydrogen gas detection based on a change in their resistivity. ${ }^{2}$ In catalysis, Pd nanostructures have been extensively employed in different fields. Pd nanowire arrays have been used as effective electrocatalysts for ethanol oxidation in direct alcohol fuel cells. ${ }^{3}$ In organic synthesis, $\mathrm{Pd}$ nanoparticles are being used widely in catalytic $\mathrm{C}-\mathrm{C}$ and $\mathrm{C}-\mathrm{N}$ bond formation reactions. ${ }^{4-8}$

Noble metal nanostructures have been synthesized using a wide range of reducing agents including organic solvents such as DMF, ethylene glycol or ethanol and inorganic reagents like hydrogen, $\mathrm{NaBH}_{4}$ and carbon monoxide. ${ }^{9-12}$ Clearly, from a 'green' perspective, some of these reducing agents carry with

Centre for Green Chemistry and Catalysis, Department of Chemistry, Memorial University of Newfoundland, St. John's, Newfoundland and Labrador, Canada A1B 3X7. E-mail: fkerton@mun.ca; Fax: +1 709 8643702; Tel: +17098648089

$\dagger$ Electronic supplementary information (ESI) available: UV-vis, MS and NMR spectra, TGA plot, additional TEM images and particle size distribution histograms, Fig. S1-S13. See DOI: 10.1039/c0gc00851f them an inherent risk. Indeed, there has been growing interest in 'greening' nanoparticle synthesis. One way of doing this is by using naturally sourced and benign reducing agents and this has been particularly successful in the formation of $\mathrm{Au}$ or $\mathrm{Ag}$ nanoparticles. For example, $\mathrm{HAuCl}_{4}$ has been reduced to $\mathrm{Au}(0)$ using glucose. ${ }^{13}$ Another interesting example is the synthesis of Au nanoparticles in a continuous fashion using ascorbic acid as the reducing agent. ${ }^{14}$ Silver nanoparticles have been prepared in aqueous solution using Capsicum annuиm L. extract. It was proposed that the proteins within the extract acted as the reducing agent. ${ }^{15}$ However, in terms of Pd nanoparticle preparation, the most widely used reagents are sources of 'active' hydrogen, e.g. $\mathrm{NaBH}_{4}$. Therefore, in order to reduce the risk of handling such reagents for the preparation of nanoparticles to be used in catalytic reactions, the nanoparticles are often formed in situ through reduction by reagents or solvent, ${ }^{16}$ but this can lead to less control over the particle size and distribution.

In order to reduce the number of components (metal precursor, solvent, stabilizer, reducing agent) in the preparation of nanoparticles, in line with the principles of green chemistry, there is growing interest in the use of ionic liquids (ILs) as stabilizing agents and reaction media in their synthesis. .,11,12,17 Modified $\mathrm{ILs}^{17}$ have been prepared that contain a reducing moiety, however, to the best of our knowledge there is no report of using commercially available phosphonium ILs as reducing agents in the synthesis of metal nanoparticles. 

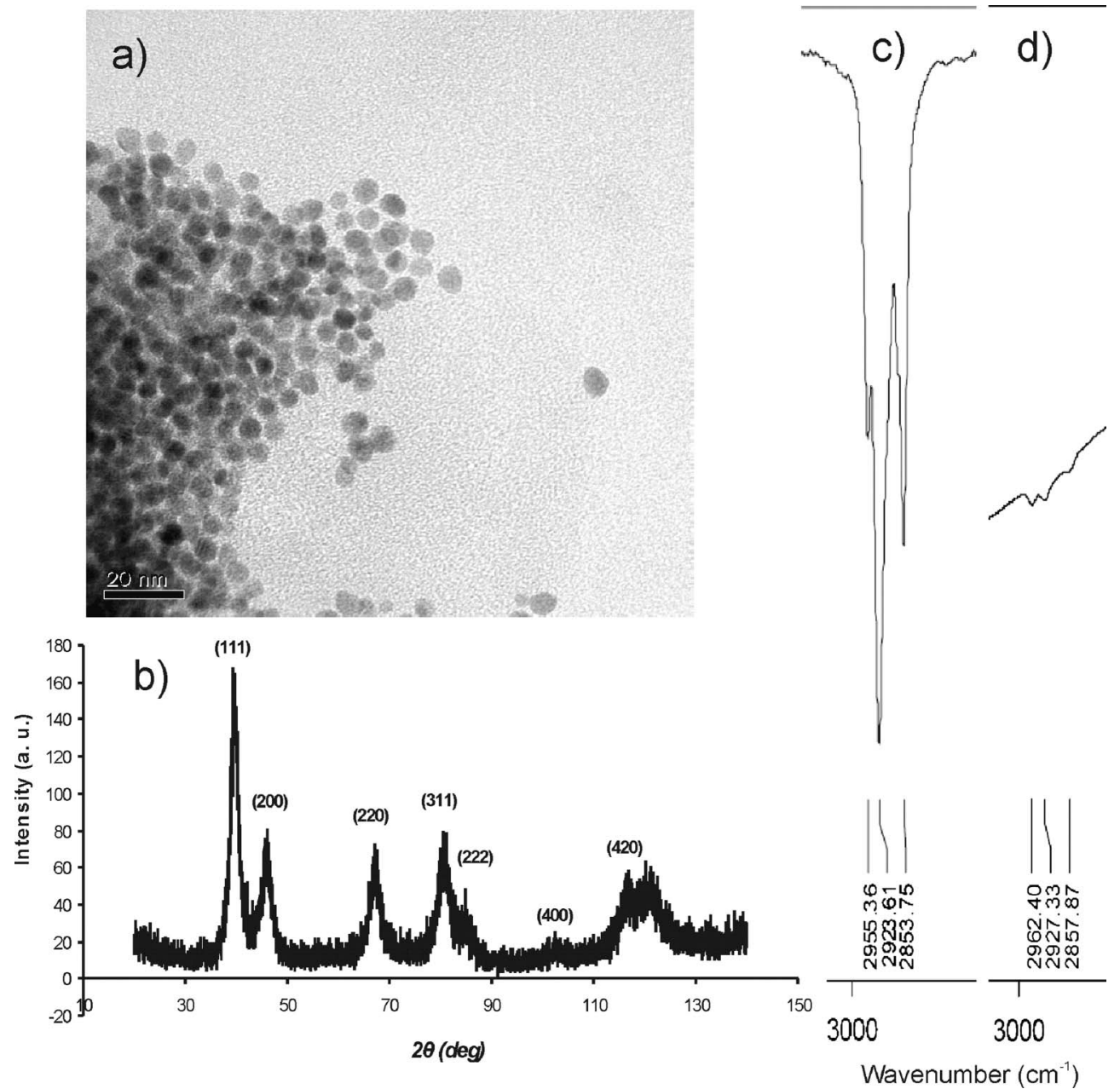

Fig. 1 Characterization of Pd nanocrystals prepared in 1. (a) TEM image. (b) X-Ray diffraction pattern. (c) and (d) Selected region of FT-IR spectra of 1 and the nanocrystals, respectively.

In this article, we report the synthesis of $\mathrm{Pd}$ nanocrystals with different shapes in phosphonium ILs composed of a trihexyl(tetradecyl)phosphonium $\left(\left[\mathrm{P}_{66614}\right]\right)$ cation and different anions without any external reducing agents. ${ }^{18}$ The ILs studied are: $\left[\mathrm{P}_{66614}\right]$ dodecylbenzenesulfonate $\mathbf{1}$, $\left[\mathrm{P}_{66614}\right]$ bis(trifluoromethylsulfonyl)amide $\quad \mathbf{2}, \quad\left[\mathrm{P}_{66614}\right]$ bis $(2,4,4-$ trimethylpentyl)phosphinate $\mathbf{3},\left[\mathrm{P}_{66614}\right]$ hexafluorophosphate $\mathbf{4}$ and $\left[\mathrm{P}_{66614}\right]$ chloride 5. Phosphonium halide ILs have been used previously as media for $\mathrm{Pd}$-catalyzed bond-forming reactions, however the presence of Pd nanoparticles was not reported. ${ }^{19}$ We also report that the nanoparticles we have prepared can be used as effective catalysts in Suzuki cross-coupling reactions.

\section{Results and discussion}

\section{Preliminary investigations}

During our study of etherification reactions in $\mathrm{ILs},{ }^{20}$ upon changing the IL from those containing imidazolium cations to $\left[\mathrm{P}_{66614}\right] \mathrm{DBS}$ (DBS = dodecylbenzenesulfonate) we discovered that the $\mathrm{Pd}(\mathrm{II})$-IL mixtures would change colour over time in the absence of any reagents. We sought to discover the origin of this colour change. $\mathrm{Pd}\left(\mathrm{CH}_{3} \mathrm{CN}\right)_{2} \mathrm{Cl}_{2}$, as the $\mathrm{Pd}(\mathrm{II})$ source, was dissolved in a capped vial containing $\left[\mathrm{P}_{66614}\right] \mathrm{DBS}$ 1. The initially orange-coloured solution was stirred at room temperature and after $1 \mathrm{~h}$ it had turned brown. UV-vis data for a sample showed good agreement with literature spectra for Pd nanoparticles (Fig. S1, ESI $\dagger$ ). ${ }^{9}$ Acetone was added to the solution and a black precipitate was separated by centrifuge. The precipitate was washed four times with acetone to remove excess 1 and dried, therefore any remaining organic groups were incorporated into the nanoparticle or on its surface. TEM images showed that the particles were truncated octahedrons (Fig. 1a and S2). Their powder XRD spectrum (Fig. 1b) matched well to face-centered cubic $(f c c)$ Pd (JCPDS card 05-0681) and the selected area electron diffraction pattern (Fig. S2) confirmed the $f c c$ crystalline structure of the product. ATR FT-IR spectra of the dry powder comprised of weak bands (symmetric and asymmetric $\mathrm{C}-\mathrm{H}$ stretches) related to $\mathbf{1}$ (Fig. 1c and $\mathrm{d}$ ). These results suggested that the IL was working as both the reducing and capping agent in the formation of the nanoparticles. Furthermore, a weight loss event below $400{ }^{\circ} \mathrm{C}$ was observed via TGA and is further proof for the presence of a capping agent on the surface of the nanocrystals. However, subsequent weight gain and loss at above $530{ }^{\circ} \mathrm{C}$ is likely related to the oxidation and reduction of $\mathrm{Pd}$ (Fig. S3). ${ }^{21}$ Although 
electrospray ionization mass spectra (both positive and negative modes) did not show any considerable differences for $\mathbf{1}$ before and after the reaction (Fig. S4 and S5), ${ }^{31} \mathrm{P}-\mathrm{NMR}$ reveals a small $0.20 \mathrm{ppm}$ downfield shift and a slight broadening of the phosphorus peak after the reaction which may be significant (Fig. S6). Size distribution histograms of the images show that the majority of the particles have sizes smaller than $9 \mathrm{~nm}$ (Fig. S7).

\section{Mechanism}

As no external inorganic or organic reagent was added to the ionic liquid solutions containing Pd(II) salts, the ionic liquid must be playing the dual role of reducing and stabilizing agent. Its role as a stabilizing agent is evident from the IR spectra of the particles and the additional defects seen in the particles when the solution is diluted with a typical organic solvent (see below) and thereby contains less stabilizing agent. However, the possible reduction mechanism is still open to debate. We propose two possible routes. Several groups have previously studied the electrochemical stability of phosphonium salts. ${ }^{22}$ The presence of current shoulders $\left(+3.2 \mathrm{~V}\right.$ vs. $\left.\mathrm{Fc} / \mathrm{Fc}^{+}\right)$has been observed in their cyclic voltammograms. ${ }^{22 c}$ These have previously been assigned to either the presence of water or a methoxy functional group in the IL. We also observe an irreversible current shoulder (oxidation) at $+1.73 \mathrm{~V} v s$. $\mathrm{Fc} / \mathrm{Fc}^{+}$for $\mathbf{1}$ in $\mathrm{CH}_{3} \mathrm{CN}(+2.20 \mathrm{~V} v s$. SCE, Fig. S8). This demonstrates that $\mathbf{1}$ is less electrochemically stable compared with the shorter alkyl chain phosphonium ILs studied by others, and that the shoulder observed in the cyclic voltammograms of some phosphonium salts is an inherent property of these species (not water or functional group dependent) and likely represents an oxidation process occurring within the alkyl chains. It is also worth noting that when the electrochemical oxidation of $\mathbf{1}$ is repeated in the presence of $\mathrm{Pd}\left(\mathrm{CH}_{3} \mathrm{CN}\right)_{2} \mathrm{Cl}_{2}$ this region of the voltammogram changes in appearance. Therefore, researchers should be aware that not all very similar ILs, e.g. phosphonium ILs with varying alkyl chain lengths, have the same useful electrochemical window and each one needs to be tested. Chu and co-workers have shown that $\left[\mathrm{P}_{66614}\right] \mathrm{Cl} 5$ can be deprotonated and undergo 'non-classical' Wittig reactions upon reaction with a suitable nucleophile. ${ }^{23}$ A first step in this process was the formation of a trialkyl phosphine, Scheme 1A. In organometallic chemistry, it is well known that reduced palladium can be formed via oxidation of phosphine ligands by oxygen from an anion (e.g. acetate or in our case DBS) or adventitious water or oxygen. ${ }^{24}$ Furthermore, via $\mathrm{GC}-\mathrm{MS}$ analysis of the volatile components from reaction mixtures, we have observed the formation of hydrocarbon chains. However, we have not observed the presence of the intermediate phosphines or product phosphine-oxides by ${ }^{31} \mathrm{P}$ NMR. Also, no distinctive odour indicative of phosphine

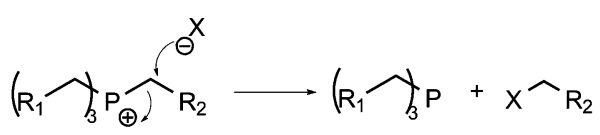

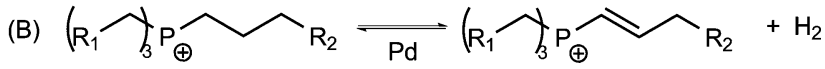

Scheme 1 Some possible reactions of trihexyl(tetradecyl)phosphonium ionic liquids. presence was noted during the preparation of the nanoparticles. Although, it should also be noted that both trialkyl phosphines and phosphine oxides can be used as stabilizing (or capping) agents in nanoparticle syntheses. If the phosphorus-containing species has become absorbed onto the Pd nanoparticle surface (as potentially indicated by TGA and IR data above), we would not expect to see a corresponding resonance in the solution NMR spectra of the IL after its use (Fig. S6). Another possible mechanism, given the microscale reversibility of many reactions, is the dehydrogenation of alkyl chains in the presence of palladium, Scheme 1B, and subsequently the hydrogen formed acts to reduce the Pd(II). Mechanism (B) may lead to the slight broadening of the resonance that we see in the ${ }^{31} \mathrm{P}$ NMR of 1 after formation of nanoparticles but at this stage mechanism (A) or other possible mechanisms (e.g. simultaneous routes such as $\mathrm{A}+\mathrm{B})$ cannot be ruled out.

\section{Effect of varying the palladium precursor}

Under the same reaction conditions, $\mathrm{Pd}(\mathrm{OAc})_{2}$ and $\mathrm{PdCl}_{2}$ also afforded nanocrystals (Fig. S2 and S9). Interestingly, $\mathrm{Pd}(\mathrm{OAc})_{2}$ yielded particles with a variety of different crystalline forms including octahedrons or triangular plates in addition to truncated octahedrons (Fig. S2, bottom). Since in $\mathrm{Pd}(\mathrm{OAc})_{2}$ there is no chloride ion source, less oxidative etching can occur and this results in the formation of more diverse nanocrystalline shapes.

\section{Effect of varying the anion of the ionic liquid}

Several other phosphonium ILs were screened for Pd nanocrystal formation using $\mathrm{Pd}\left(\mathrm{CH}_{3} \mathrm{CN}\right)_{2} \mathrm{Cl}_{2}$ as the $\mathrm{Pd}$ precursor. $\left[\mathrm{P}_{66614}\right]$ bis(trifluoromethylsulfonyl)amide $\mathbf{2}$ yielded truncated octahedrons (Fig. S10) with a narrow size range. In contrast, under the same room temperature reaction conditions no colour change was observed when using $\left[\mathrm{P}_{66614}\right]$ bis $(2,4,4-$ trimethylpentyl)phosphinate 3 and $\left[\mathrm{P}_{66614}\right] \mathrm{PF}_{6} \mathbf{4}$, however, after $5 \mathrm{~h}$ at $100{ }^{\circ} \mathrm{C}$ octahedrons and triangular plates of $\mathrm{Pd}$ were the major products in 3 (Fig. 2) and after $15 \mathrm{~h}$ at $80^{\circ} \mathrm{C}$ a mixture of truncated octahedrons and octahedrons of $\mathrm{Pd}$ were formed in 4 (Fig. S11). For a $f c c$ structure octahedron or tetrahedron shapes have the lowest total surface energy. This is despite a truncated octahedron, which has a semispherical shape, having a smaller surface area with more $\{111\}$ and $\{100\}$ facets and lower interfacial free energy. ${ }^{9,25}$

Oxidative etching of $\mathrm{Pd}$ can happen in the presence of $\mathrm{O}_{2}$ and $\mathrm{Cl}^{-}$, and twinned particles (octahedrons) are known to be etched faster than single crystals (truncated octahedrons). ${ }^{26,27}$ Therefore truncated octahedron structures are those most likely to form under our reaction conditions, unless a stabilizing agent can attach to $\{111\}$ facets (in the case of an octahedron) and prevent the oxidative etching from occurring (Fig. 2). As when 3 is used, octahedron-shaped structures are seen, the bis $(2,4,4-$ trimethylpentyl)phosphinate anion must also be involved in the

\$ The need to heat $\mathbf{3}$ and $\mathbf{4}$ to achieve nanoparticle formation is due to the comparatively high viscosity of $\mathbf{3}$ and because $\mathbf{4}$ is a solid at room temperature. $\mathbf{4}$ melts and $\mathbf{3}$ becomes less viscous upon heating and thus allows palladium seed particles to migrate through the IL phase and form nanocrystals. 

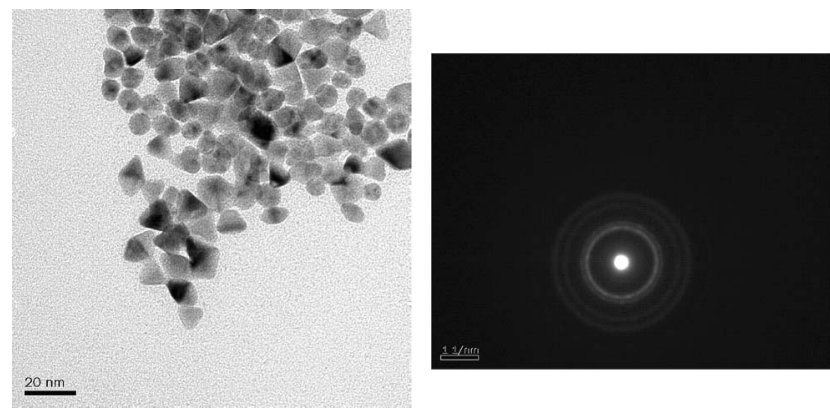

Fig. 2 TEM image of the Pd nanocrystals prepared in $\mathbf{3}$ and the corresponding selected area electron diffraction pattern.

stabilizing process and prevents etching. Etching may also be the reason why no nanoparticles were observed when the reaction was performed in $\left[\mathrm{P}_{66614}\right] \mathrm{Cl} 5$ even at elevated temperatures, while the anions in the other ILs can stabilize the nanocrystal seeds and slow down any oxidative etching.

\section{Effect of oxygen levels}

Although $\mathrm{Cl}^{-}$was present in most of the reaction mixtures, reactions were repeated under oxygen-free conditions in order to assess any oxidative etching effects. For example, two reaction mixtures were prepared using 1 and $\operatorname{Pd}\left(\mathrm{CH}_{3} \mathrm{CN}\right)_{2} \mathrm{Cl}_{2}$. One of the samples was transferred to a glove box under a nitrogen atmosphere and the other was kept in a capped vial on the benchtop. The sample in the glove box changed colour much faster than the sample outside (Fig. S12) indicating that nanocrystal formation is inhibited by the presence of $\mathrm{O}_{2}$. However, it should be noted that suspensions of nanoparticles in 1-3 are stable (showing no evidence of precipitate formation) upon storage in capped vials on a benchtop for at least 3 months.

\section{Effect of IL concentration}

As ILs are quite expensive, we wanted to see if smaller amounts of ILs could be used in solution to yield nanoparticles. A $\mathrm{Pd}\left(\mathrm{CH}_{3} \mathrm{CN}\right)_{2} \mathrm{Cl}_{2}$ solution composed of a $1: 1$ mole ratio of 1 and THF yielded 'merged' Pd nanocrystals (Fig. 3 and $\mathrm{S} 13)$. Since coalescence of particles in the less viscous reaction solution (THF+IL) is more probable and also there is a lower concentration of stabilizer, more stacking faults were observed in TEM images of these samples (one of these faults has been highlighted by an arrow in Fig. 3a).

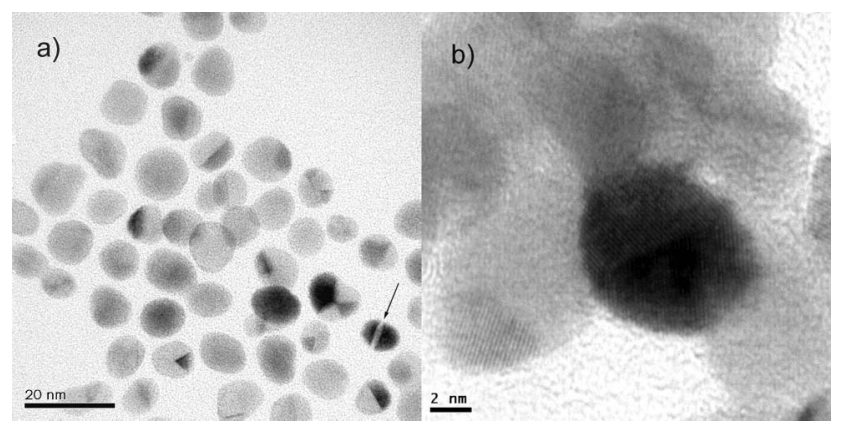

Fig. 3 (a) TEM and (b) HRTEM images, respectively, of the Pd nanocrystals prepared from $\mathrm{Pd}\left(\mathrm{CH}_{3} \mathrm{CN}\right)_{2} \mathrm{Cl}_{2}$ in a $1: 1$ mole ratio of $\mathbf{1}$ and THF at room temperature.
Table 1 Suzuki coupling reaction of 4-bromotoluene and benzene boronic acid in $\left[\mathrm{P}_{66614}\right]$ DBS using Pd nanocrystals and different bases

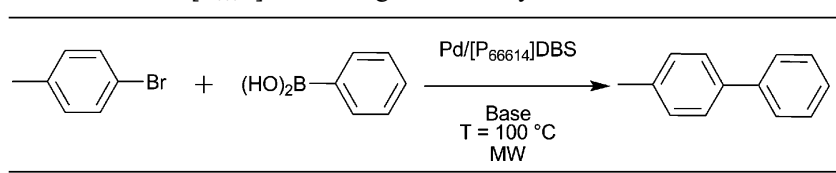

\begin{tabular}{lllll}
\hline Entry & Base & $\begin{array}{l}\text { Base/Bromotoluene } \\
(\text { mole ratio) }\end{array}$ & Time/min & Yield $(\%)^{a}$ \\
\hline 1 & $\mathrm{KOH}$ & 1.1 & 10 & 50 \\
2 & $\mathrm{KOH}$ & 1.1 & 15 & 60 \\
3 & Triethylamine & 1.1 & 10 & 9 \\
4 & $\mathrm{~K}_{2} \mathrm{CO}_{3} \cdot \mathrm{H}_{2} \mathrm{O}$ & 1.6 & 15 & 78 \\
5 & $\mathrm{KOH}_{6}$ & 1.8 & 15 & 90 \\
$\mathrm{Cs}_{2} \mathrm{CO}_{3}$ & 2.0 & $15(2 \times 15)$ & $43(75)$
\end{tabular}

${ }^{a}$ Yields were calculated relative to 4 -bromotoluene using ${ }^{1} \mathrm{H}-\mathrm{NMR}$ spectroscopy with acetophenone as the internal standard.

\section{Preliminary results using phosphonium-stabilized $\mathbf{P d}$ nanoparticles as catalysts}

As an important use of Pd nanoparticles is in catalysis, a Suzuki reaction was carried out using in situ prepared Pd nanocrystals in 1 under microwave irradiation. A high yield was obtained when 4-bromotoluene was reacted with benzene boronic acid in the presence of potassium hydroxide (Table 1). TEM images of the Pd nanocrystals after the Suzuki reaction showed that the reaction does not affect the shapes and the sizes of the nanoparticles (Fig. 4). However, no tests were performed in situ on the catalytic reaction mixtures to definitely prove the nature of the active catalytic species. The active species might not be the nanocrystals themselves but the nanocrystals may be acting as a reservoir of soluble Pd. Nanocrystals with different shapes based on their crystal facets can have different catalytic activities and selectivities in a chemical reaction., ${ }^{9,26}$ Therefore, future work will involve preparing Pd nanocrystals with different shapes based on this method in order to investigate the relationship between shape and reactivity.

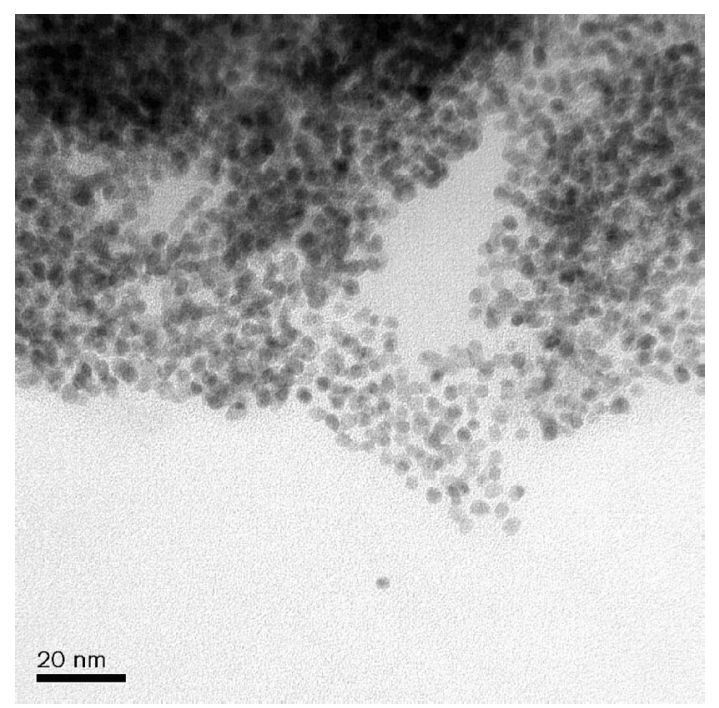

Fig. 4 TEM image of the Pd nanocrystals after the Suzuki reaction. 


\section{Conclusions}

We have described a simple method for preparing Pd nanocrystals with different shapes without using any external reducing agents. In this method, phosphonium ILs have been used as both reducing and stabilizing agents. This work provides further evidence of the useful nature of phosphonium-derived ILs in reduction chemistry. ${ }^{29}$ This method circumvents the need for additional reagents in the formation of the particles as the IL acts as the medium, reducing agent and stabilizer for the process. This in some way reduces the risk and hazards associated with the preparation of Pd nanoparticles. However, it cannot be ignored that phosphonium ILs themselves are known to be toxic, ${ }^{28}$ and therefore the quest for truly benign syntheses of $\mathrm{Pd}$ nanoparticles continues. The in situ prepared Pd nanocrystals showed good catalytic activity in a Suzuki cross-coupling reaction.

\section{Experimental}

\section{General information and instrumentation}

$\mathrm{PdCl}_{2}$ was purchased from Precious Metals Online. The ionic liquids $\left[\mathrm{P}_{66614}\right] \mathrm{DBS}$ (Cyphos phosphonium IL 202) and $\left[\mathrm{P}_{66614}\right] \mathrm{Cl}$ (Cyphos phosphonium IL 101) were gift samples from Cytec Industries and the other ILs were purchased from SigmaAldrich. Nanoparticles were prepared using ILs as they were received and ILs purified using a literature method, ${ }^{29}$ but the same results were obtained using purified and 'as received' batches of ILs.

TEM images were obtained using a JEOL 2011 high resolution $(200 \mathrm{kV})$ Scanning Transmission Electron Microscope (STEM) with EDAX (Genesis) Energy Dispersive X-ray system at the University of New Brunswick. Samples were shipped to New Brunswick as suspensions in acetone that had been reconstituted from nanoparticulate dry powders. The suspensions were sonicated before sampling in order to have a homogeneous dispersion of particles. TEM images were taken by putting a drop of nanoparticle suspension in acetone on a carbon coated copper grid. Image J software was used to obtain size distribution histograms.

Infrared spectra were obtained using a Bruker TENSOR 27 infrared spectrometer equipped with a MIRacle ATR (Attenuated Total Reflection). ${ }^{31} \mathrm{P}-\mathrm{NMR}$ spectra were obtained on a Bruker AVANCE II 600 spectrometer (referenced with respect to $85 \% \mathrm{H}_{3} \mathrm{PO}_{4}$ at $0.00 \mathrm{ppm}$ ). An Ocean Optics UV-vis spectrophotometer was used for UV-vis spectroscopy and the IL-nanoparticle suspensions were diluted in dichloromethane. $\mathrm{X}$-Ray diffraction analyses were performed on a Rigaku Ultima IV with cross-beam optics (CBO). Bragg-Brentano mode was used for the analysis. $\mathrm{Cu}$ was used as the X-ray source $(40 \mathrm{kV}$ and $44 \mathrm{~mA}$ ). For the TGA analysis, a TA Instruments Q500 was used and the sample was loaded onto a platinum pan. The

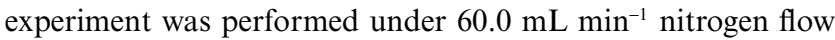
with a temperature increase rate of $20^{\circ} \mathrm{C} \mathrm{min}^{-1}$. An Agilent 1100 $\mathrm{LC} / \mathrm{MSD}$ instrument was used for the electrospray ionization spectrometry (ESI-MS) and all samples were diluted in acetone prior to analysis. A Biotage Initiator 2.5 microwave reactor was employed for the Suzuki reactions. $0.5-2 \mathrm{~mL}$ microwave vials with PTFE seals were used for all the experiments.

\section{Preparation of Pd nanocrystals}

$\mathrm{Pd}\left(\mathrm{CH}_{3} \mathrm{CN}\right)_{2} \mathrm{Cl}_{2}(0.0072 \mathrm{~g}, 0.028 \mathrm{mmol})$ was dissolved in degassed IL $(0.500 \mathrm{~g})$ in a vial capped under nitrogen flow. For $\mathbf{1}$ or $\mathbf{2}$, the solution was stirred for $18 \mathrm{~h}$ at room temperature. For ILs 3 and 4, the reaction mixtures were heated to $100^{\circ} \mathrm{C}$ for $5 \mathrm{~h}$ and $80^{\circ} \mathrm{C}$ for $15 \mathrm{~h}$, respectively. The reaction mixtures were monitored using UV-Vis spectroscopy for the disappearance of $\mathrm{Pd}^{2+}$. Acetone $(3 \times 3 \mathrm{~mL})$ was added to the brown reaction mixture to precipitate the Pd nanoparticles and remove the IL. The resulting fine black powder was isolated from acetone via centrifuge and dried under vacuum for $18 \mathrm{~h}$ prior to analysis using FT-IR, TGA and XRD. Nanoparticles were redispersed in acetone for TEM sample preparation. The ILs were recovered from the acetone washings and analysed via ESI-MS and NMR spectroscopy. ESI-MS and NMR experiments were also performed on the reaction mixtures themselves.

\section{Experimental for the Suzuki reactions}

In a typical reaction, $\mathrm{Pd}\left(\mathrm{CH}_{3} \mathrm{CN}\right)_{2} \mathrm{Cl}_{2}(0.0058 \mathrm{~g}, 2.7 \mathrm{~mol} \%)$ was dissolved in degassed $\left[\mathrm{P}_{66614}\right]$ DBS $1(0.563 \mathrm{~g})$ in a vial capped under nitrogen flow. The solution was stirred until it turned deep brown in colour indicating that Pd nanocrystals had formed.§ 4-Bromotoluene $(0.141 \mathrm{~g}, 0.825 \mathrm{mmol})$, benzeneboronic acid $(0.130 \mathrm{~g}, 1.07 \mathrm{mmol})$ and $\mathrm{KOH}(0.082 \mathrm{~g}, 1.47 \mathrm{mmol})$ was added to the reaction mixture $(\mathrm{KOH}$ was ground to a powder before addition). This reaction mixture was capped again and sealed under a nitrogen blanket. The reaction was heated in a Biotage MW system for $15 \mathrm{~min}$ at $100{ }^{\circ} \mathrm{C}$ (the absorptivity on the MW was set at "high"). The vial was opened and the product isolated from the $\left[\mathrm{P}_{66614}\right] \mathrm{DBS} / \mathrm{Pd} /$ Base mixture by vacuum distillation. (Note: For other ionic liquids, solvent extraction of the products could be performed.)

\section{Acknowledgements}

We acknowledge support from NSERC and Canada Foundation for Innovation in the form of a Discovery Grant, a Research Tools and Instrument Grant and a Leaders Opportunity Fund Award (F. M. K.). We would also like to thank Memorial University for funding and Cytec Industries Inc. for samples of $\left[\mathrm{P}_{66614}\right] \mathrm{DBS}$ and $\left[\mathrm{P}_{66614}\right] \mathrm{Cl}$. Dr Louise Weaver (University of New Brunswick, Canada) is thanked for obtaining TEM images and Prof. Peter Pickup and Mr Rodney Smith (Memorial University) for access to electrochemical equipment.

\section{Notes and references}

1 (a) V. Polshettiwar and R. S. Varma, Green Chem., 2010, 12, 743-754; (b) S. Wang, Z. Wang and Z. Zha, Dalton Trans., 2009, 9363-9373; (c) D. Astruc, F. Lu and J. Ruiz Aranzaes, Angew. Chem., Int. Ed., $2005,44,7852-7872$.

2 F. Favier, E. C. Walter, M. P. Zach, T. Benter and R. M. Penner, Science, 2001, 293, 2227-2231.

3 C. Xu, H. Wang, P. K. Shen and S. P. Jiang, Adv. Mater., 2007, 19, 4256-4259.

$\S \mathrm{Pd}\left(\mathrm{CH}_{3} \mathrm{CN}\right)_{2} \mathrm{Cl}_{2}$ could also potentially be the pre-catalyst for this reaction. However, UV-Vis analysis of the nanoparticle/IL suspension confirms the absence of this Pd precursor in the IL. 
4 Y. Chen, H. Hung and M. H. Huang, J. Am. Chem. Soc., 2009, 131, 9114-9121.

5 J. C. Garcia-Martinez, R. Lezutekong and R. M. Crooks, J. Am. Chem. Soc., 2005, 127, 5097-5103.

6 (a) X. Yang, Z. Fei, D. Zhao, W. Han Ang, Y. Li and P. J. Dyson, Inorg. Chem., 2008, 47, 3292-3297; (b) Y. Cui, I. Biondi, M. Chaubey, X. Yang, Z. Fei, R. Scopelliti, C. G. Hartinger, Y. Li, C. Chiappe and P. J. Dyson, Phys. Chem. Chem. Phys., 2010, 12, 1834-1841.

7 C. C. Cassol, A. P. Umpierre, G. Machado, S. I. Wolke and J. Dupont, J. Am. Chem. Soc., 2005, 127, 3298-3299.

8 L. Adak, K. Chattopadhyay and B. C. Ranu, J. Org. Chem., 2009, 74, 3982-3985.

9 B. Lim, M. Jiang, J. Tao, P. H. C. Camargo, Y. Zhu and Y. Xia, $A d v$. Funct. Mater., 2009, 19, 189-200.

10 P. F. Siril, L. Ramos, P. Beaunier, P. Archirel, A. Etcheberry and H. Remita, Chem. Mater., 2009, 21, 5170-5175.

11 Z. Yinghuai, E. Widjaja, S. L. P. Sia, W. Zhan, K. Carpenter, J. A. Maguire, N. S. Hosmane and M. F. Hawthorne, J. Am. Chem. Soc., 2007, 129, 6507-6512.

12 V. Cimpeanu, M. Kočevar, V. I. Parvulescu and W. Leitner, Angew. Chem., Int. Ed., 2009, 48, 1085-1088.

13 (a) P. Raveendran, J. Fu and S. L. Wallen, Green Chem., 2006, 8, 34 38; (b) J. Liu, G. Qin, P. Raveendran and Y. Ikushima, Chem.-Eur. J., 2006, 12, 2131-2138.

14 J. Wagner and J. M. Köhler, Nano Lett., 2005, 5, 685-691.

15 S. Li, Y. Shen, A. Xie, X. Yu, L. Qiu, L. Zhang and Q. Zhang, Green Chem., 2007, 9, 852-858.

16 For example: (a) L. Adak, K. Chattopadhyay and B. C. Ranu, J. Org. Chem., 2009, 74, 3982-3985; (b) P. Wang, Q. Lu and J. Li, Catal. Lett., 2009, 131, 444-450; (c) S. Saffarzadeh-Matin, F. M. Kerton, J. M. Lynam and C. M. Rayner, Green Chem., 2006, 8, 965-971.

17 A. Safavi, N. Maleki, N. Iranpoor, H. Firouzabadi, A. R. Banazadeh, R. Azadi and F. Sedaghati, Chem. Commun., 2008, 6155-6157.

18 One communication has been published concerning 'reductant-free' synthesis of Pd nanocrystals: F. Y. Norimatsu, Y. Mizokoshi, K. Mori, T. Mizugaki, K. Ebitani and K. Kaneda, Chem. Lett., 2006,
35, 276-277. In this example, it is likely that the solvent $N, N$ dimethylacetamide or carbon monoxide (present in the Pd precursor complex) were the reducing agents.

19 For example: (a) H. Cao, L. McNamee and H. Alper, Org. Lett., 2008, 10, 5281-5284; (b) D. A. Gerritsma, A. Robertson, J. McNulty and A. Capretta, Tetrahedron Lett., 2004, 45, 7629-7631; (c) J. McNulty, S. Cheekoori, T. P. Bender and J. A. Coggan, Eur. J. Org. Chem., 2007, 1423-1428; (d) J. McNulty, J. J. Nair and A. Robertson, Org. Lett., 2007, 9, 4575-4578.

20 H. A. Kalviri, C. F. Petten and F. M. Kerton, Chem. Commun., 2009, 5171-5173

21 P. K. Khanna, N. Singh, D. Kulkarni, R. Marimuthu, S. Charan, K. R. Patil and G. H. Jain, Synth. React. Inorg., Met.-Org., NanoMet. Chem., 2007, 37, 531-539.

22 For example: (a) A. I. Bhatt, I. May, V. A. Volkovich, M. E. Hetherington, B. Lewin, R. C. Thied and N. Ertok, J. Chem. Soc., Dalton Trans., 2002, 4532-4534; (b) E. Frackowiak, G. Lota and J. Pernak, Appl. Phys. Lett., 2005, 86, 164104; (c) K. Tsunashima and M. Sugiya, Electrochem. Commun., 2007, 9, 2353-2358.

23 M.-C Tseng, H.-C Kan and Y.-H. Chu, Tetrahedron Lett., 2007, 48, 9085-9089.

24 (a) C. Amatore, A. Jutand and M.-A. M'Barki, Organometallics, 1992, 11, 3009-3013; (b) C. Amatore, E. Carre, A. Jutand and M.-A. M'Barki, Organometallics, 1995, 14, 1818-1826.

25 B. Lim, Y. Xiong and Y. Xia, Angew. Chem., Int. Ed., 2007, 46, 9279-9282.

26 Y. Xiong, J. M. McLellan, Y. Yin and Y. Xia, Angew. Chem., Int. Ed., 2007, 46, 790-794.

27 M. Tsuji, Y. Maeda, S. Hikino, H. Kumagae, M. Matsunaga, X. Tang, R. Matsuo, M. Ogino and P. Jiang, Cryst. Growth Des., 2009, 9, 4700-4705.

28 R. F. M. Frade, A. Matias, L. C. Branco, C. A. M. Afonso and C. M. M. Duarte, Green Chem., 2007, 9, 873-877.

29 T. Ramnial, S. A. Taylor, M. L. Bender, B. Gorodetsky, P. T. K. Lee, D. A. Dickie, B. M. McCollum, C. C. Pye, C. J. Walsby and J. A. C. Clyburne, J. Org. Chem., 2008, 73, 801-812. 